\title{
EFFECTS OF CARDIOPULMONARY BYPASS AND CIRCULATORY ARREST ON ENDOTHELIUM- DEPENDENT VASODILATATION IN THE LUNG
}

Paul M. Kirshbom, MD

Michael T. Jacobs, BS

Steven S. L. Tsui, FRCS ${ }^{\mathrm{a}}$

Louis R. DiBernardo, $\mathrm{MD}^{\mathrm{a}}$

Debra A. Schwinn, MD $^{\mathrm{a}, \mathrm{b}, \mathrm{c}}$

Ross M. Ungerleider, $\mathrm{MD}^{\mathrm{a}}$

J. William Gaynor, $\mathrm{MD}^{\mathrm{a} *}$
Endothelial injury with failure of pulmonary endothelium-dependent vasodilatation has been proposed as a possible cause for the increased pulmonary vascular resistance observed after cardiopulmonary bypass, but the mechanisms underlying this response are not understood. An in vivo piglet model was used to investigate the role of endothelium-dependent vasodilatation in postbypass pulmonary hypertension. The pulmonary vascular responses to acetylcholine, a receptor-mediated endotheliumdependent vasodilator, and nitric oxide, an endothelium-independent vasodilator, were studied in one group of animals after preconstriction with the thromboxane $A_{2}$ analog $U 46619(n=6)$; a second group was studied after bypass with 30 minutes of deep hypothermic circulatory arrest $(n=$ 6). After preconstriction with $U \mathbf{4 6 6 1 9}$, both acetylcholine and nitric oxide caused significant decreases in pulmonary vascular resistance $(34 \% \pm 6 \%$ decrease, $p=0.007$, and $39 \% \pm 4 \%$ decrease, $p=0.001$ ). After cardiopulmonary bypass with circulatory arrest, acetylcholine did not significantly change pulmonary vascular resistance $(0 \% \pm 8 \%$ decrease, $p=1.0)$, whereas nitric oxide produced a $32 \% \pm 4 \%$ decrease in pulmonary vascular resistance $(p=0.007)$. These results demonstrate a loss of receptormediated endothelium-dependent vasodilatation with normal vascular smooth muscle function after circulatory arrest. Administration of the nitric oxide synthase blocker $N \gamma$-nitro-L-arginine-methyl-ester after circulatory arrest significantly increased pulmonary vascular resistance; thus, although endothelial cell production of nitric oxide may be diminished, it continues to be a major contributor to pulmonary vasomotor tone after cardiopulmonary bypass with deep hypothermic circulatory arrest. In summary, cardiopulmonary bypass with deep hypothermic circulatory arrest results in selective pulmonary endothelial cell dysfunction with loss of receptor-mediated endothelium-dependent vasodilatation despite preserved ability of the endothelium to produce nitric oxide and intact vascular smooth muscle function. (J Thorac Cardiovasc Surg 1996;111:1248-56)
Puln ulmonary hypertension associated with elevated pulmonary vascular resistance (PVR) can be a significant problem after the use of cardiopulmonary bypass (CPB) with deep hypothermic circula-

From the Departments of Surgery, ${ }^{a}$ Anesthesiology, ${ }^{\mathrm{b}}$ and Pharmacology, ${ }^{\mathrm{c}}$ Duke University Medical Center, Durham, N.C.

Received for publication May 30, 1995; accepted for publication August 28, 1995.

Address for reprints: J. William Gaynor, MD, Pediatric Cardiothoracic Surgery, Children's Hospital of Philadelphia, 34th St. and Civic Center Blvd., Philadelphia, PA 19104.

${ }^{*}$ Present address ${ }^{\mathrm{d}}$ : Department of Pediatric Cardiothoracic Surgery, Children's Hospital of Philadelphia, Philadelphia, Pa.

Copyright (C 1996 by Mosby-Year Book, Inc.

$0022-5223 / 96 \$ 5.00+0 \quad \mathbf{1 2} / \mathbf{1} / \mathbf{6 8 9 0 6}$ tory arrest (DHCA) for the repair of congenital cardiac disease..$^{1-3}$ Pulmonary vasomotor tone is determined by the balance between competing effects of vasoconstrictors and vasodilators. The endothelium produces vasoconstrictors and vasodilators that affect pulmonary vasomotor tone; however, the factors that modulate PVR in vivo have not been fully delineated. The vasodilator nitric oxide is produced by endothelial cells from the precursor amino acid L-arginine and is important in the maintenance of the normally low PVR. ${ }^{4}$ Endothelium-dependent vasodilators, such as acetylcholine, stimulate endothelial production of vasodilating agents, the most significant of which is nitric oxide. Endotheliumindependent vasodilators, such as inhaled nitric 


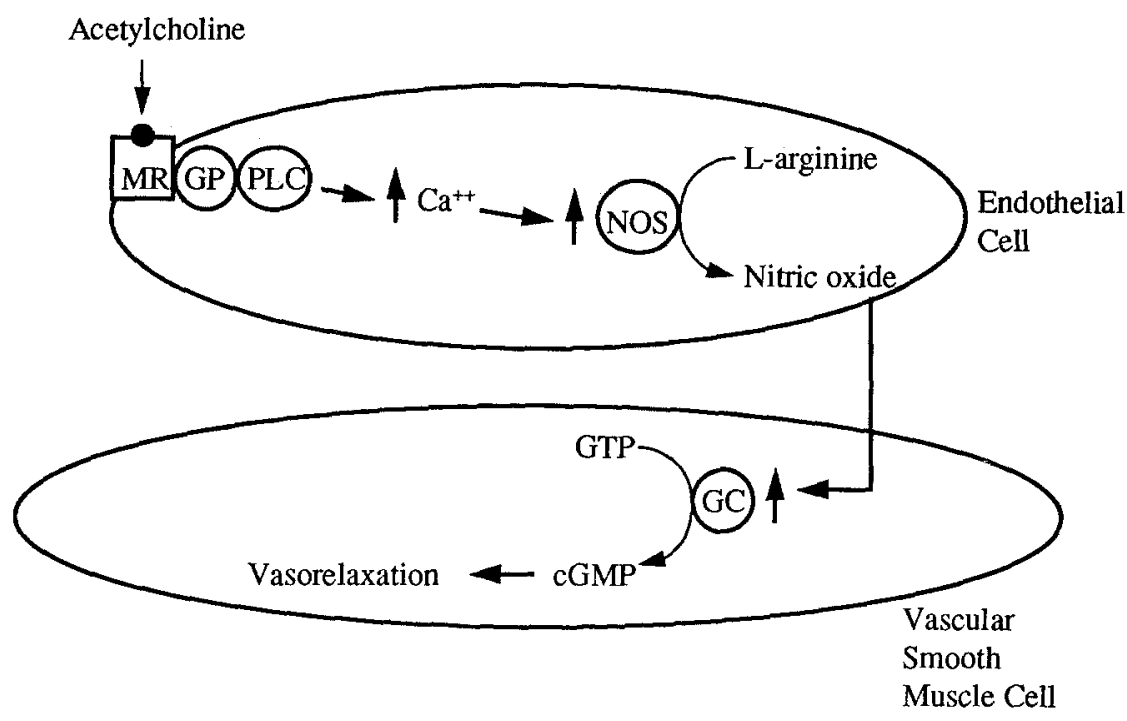

Fig. 1. Endothelium-dependent vasodilation. Acetylcholine binds to the muscarinic receptor (MR) triggering an increase in cytosolic calcium $\left(\mathrm{Ca}^{++}\right)$concentrations through a $\mathrm{G}$ protein $(G P)$-phospholipase C (PLC) second messenger system. Nitric oxide synthase (NOS) is stimulated by the increase in $\mathrm{Ca}^{++}$ resulting in increased nitric oxide production from L-arginine $(L$-arg). Nitric oxide $(N O)$ diffuses into the vascular smooth muscle cell and stimulates guanylate cyclase $(G C)$, which converts guanosine triphosphate $(G T P)$ to cyclic guanosine monophosphate $(c G M P)$. Cyclic guanosine monophosphate then triggers smooth muscle cell relaxation.

oxide or sodium nitroprusside, act directly on the vascular smooth muscle. Endothelial dysfunction, manifested as impaired endothelium-dependent pulmonary vasodilatation in response to acetylcholine, has been documented in children after CPB. ${ }^{2}$ Decreased responsiveness to endothelium-dependent vasodilators after CPB has been postulated to result from a loss of nitric oxide production resulting from endothelial cell injury; however, the mechanisms involved remain unclear.

Endothelium-dependent vasodilators can be classified as either receptor-mediated or receptor-independent agents. Receptor-mediated vasodilators, including acetylcholine and adenosine diphosphate, act via their receptor located on the endothelial cell surface to stimulate nitric oxide production. Receptor-independent endothelium-dependent agents, including phospholipase $\mathrm{C}$ and the calcium ionophore A23187, do not act through a membrane receptor to stimulate nitric oxide production. ${ }^{5}$ Acetylcholine provides a useful paradigm for receptor-mediated endothelium-dependent vasodilatation (Fig. 1), 6 with the muscarinic receptor on the endothelial cell surface linked to production of nitric oxide through a guanine nucleotide regulatory protein or $\mathrm{G}$ protein. G proteins are heterotrimeric membrane-asso- ciated proteins that transduce receptor-generated signals to second messenger systems, which then alter cellular activity. ${ }^{6}$ In vascular endothelial cells, stimulation of the muscarinic receptor-G protein complex activates the production of inositol triphosphate by phospholipase $\mathrm{C}$, which triggers an increase in the cytosolic calcium ion concentration. Nitric oxide synthase activity is increased by elevations in cytosolic calcium in endothelial cells, resulting in increased production of nitric oxide from L-arginine. Nitric oxide then diffuses into the adjacent vascular smooth muscle and stimulates guanylate cyclase, which converts guanosine triphosphate to cyclic guanosine monophosphate. Increased levels of cyclic guanosine monophosphate result in smooth muscle cell relaxation. Failure of any step in this sequence could result in decreased receptormediated endothelium-dependent vasodilatation.

The current study was undertaken to evaluate the mechanisms underlying diminished receptor-mediated endothelium-dependent vasodilatation after CPB in an in vivo animal model. Validation of the model requires demonstration of normal endothelial and vascular smooth muscle function before $\mathrm{CPB}$ and failure of receptor-mediated endotheliumdependent vasodilatation after CPB. 


\section{Materials and methods}

Anesthesia and surgery. Forty DeKalb piglets (4 to 6 weeks old and weighing 9 to $13 \mathrm{~kg}$ ) were studied in four separate protocols. All animals received humane care in accordance with the "Guide for the Care and Use of Laboratory Animals" published by the National Institutes of Health (NIH publication No. 85-23, revised 1985) and as approved by the Duke University Medical Center Animal Care and Use Committee. The same anesthesia and CPB techniques were used for the three experiments.

Anesthesia was induced with intramuscular ketamine $(20 \mathrm{mg} / \mathrm{kg}$ ) and acepromazine $(1 \mathrm{mg} / \mathrm{kg})$. The piglets were intubated and mechanical ventilation (Sechrist Infant Ventilator, model IV-100B, Sechrist Industries, Inc., Anaheim, Calif.) was begun. Anesthesia was maintained with fentanyl $(100 \mu \mathrm{g} / \mathrm{kg}$ bolus and $50 \mu \mathrm{g} / \mathrm{kg}$ per hour continuous infusion) and pancuronium $(0.3 \mu \mathrm{g} / \mathrm{kg})$. The ventilator was set with a positive inspiratory pressure of $25 \mathrm{~mm}$ $\mathrm{Hg}$ and a positive end-expiratory pressure of $3 \mathrm{~mm} \mathrm{Hg}$. Respiratory rate and inspired oxygen fraction were titrated to maintain an arterial carbon dioxide tension of 35 to $45 \mathrm{~mm} \mathrm{Hg}$ and an oxygen tension of 150 to $250 \mathrm{~mm} \mathrm{Hg}$. Sodium bicarbonate $(8.5 \%)$ was used to maintain a base excess between -3 and $3 \mathrm{mmol} / \mathrm{L}$. All animals received methylprednisolone ( $25 \mathrm{mg} / \mathrm{kg}$ intravenously) before the operation.

A femoral arterial line was placed for blood pressure monitoring and arterial blood gas sampling. A nasopharyngeal temperature probe (Yellow Springs Instrument Company, Yellow Springs, Ohio, YSI-400) was inserted and a median sternotomy was performed. The pericardium was opened and a $10 \mathrm{~mm}$ ultrasonic flow probe was placed on the main pulmonary artery (Transonic Systems Inc., Ithaca, N.Y.). Micromanometers (3F, Millar Instruments, Inc., Houston, Tex.) were placed in the pulmonary artery and left atrium and a 24-gauge infusion catheter was placed in the pulmonary artery.

CPB. Purse-string sutures of 2-0 silk and 5-0 Prolene polypropylene (Ethicon, Inc., Somerville, N.J.) were placed in the right atrial appendage and aortic root, respectively. Animals were given heparin $(500 \mathrm{IU} / \mathrm{kg})$ and cannulated with a $10 \mathrm{~F}$ infant arterial cannula and a $28 \mathrm{~F}$ venous cannula (Electro-catheter Corp., Rahway, N.J.). The CPB circuit consisted of a Stockert Shiley roller pump (Shiley Inc., Irvine, Calif., model 10-10-00), a Cobe membrane oxygenator (Cobe Laboratory, Lakewood, Colo.), and a Bio-Cal 370 heat exchanger (Medtronic Bio-Medicus, Minneapolis, Minn.). The pump was primed with crystalloid solution and fresh donor pig blood to maintain a circuit hematocrit value of $18 \%$ to $20 \%$.

The piglets were cooled over 20 minutes to a nasopharyngeal temperature of $18^{\circ} \mathrm{C}$, the hearts were arrested for either 30 or 60 minutes, the animals were rewarmed over 30 minutes to $37^{\circ} \mathrm{C}$, and they were weaned from CPB. Saline slush was used for topical myocardial hypothermia during cooling and circulatory arrest. The hearts became asystolic during cooling and occasionally fibrillated during rewarming, necessitating direct-current cardioversion with 1 to 2 joules. No animal required more than two defibrillations. CPB circuit volume was returned to the animals as needed to maintain a stable left atrial pressure and cardiac output after weaning from CPB. No inotropic agents were used. Animals were studied 15 minutes after weaning from CPB while in a steady-state condition with arterial blood gases within the limits previously described in the Anesthesia and surgery section.

Assessment of endothelium-dependent and endothelium-independent vasodilatation. Receptor-mediated endothelium-dependent vasodilatation was assessed with a continuous infusion of acetylcholine at a rate of $12.5 \mu \mathrm{g} / \mathrm{kg}$ per minute into the pulmonary artery line. Data were acquired before and 5 minutes after the acetylcholine infusion was begun ( 5 minutes of infusion was found to be sufficient to achieve a steady-state effect in preliminary studies).

Endothelium-independent vasodilatation was assessed with nitric oxide 10 minutes after discontinuation of acetylcholine (the amount of time that was determined in preliminary studies to be sufficient for the animals to return to baseline). Data were collected immediately before and 5 minutes after institution of inhalational nitric oxide at twenty parts per million (ppm) through the ventilator circuit. Inhalational nitric oxide concentration was monitored with a chemiluminescence nitric oxide analyzer (model $42 \mathrm{H}$, Thermo Environmental Instruments, Franklin, Mass.). Nitrogen dioxide concentrations were also monitored and did not exceed 1 ppm.

Data collected included pulmonary artery and left atrial pressures, pulmonary artery flow (cardiac output), mean arterial pressure, heart rate, and arterial blood gases. Pressure and flow data were collected at $200 \mathrm{~Hz}$ over 10 seconds with the ventilator placed at a $3 \mathrm{~mm} \mathrm{Hg}$ continuous positive airway pressure. PVR was calculated with the following formula:

$$
P V R=(P A P-L A P) / C O \times 1330 \text { dynes } / \mathrm{mm} \mathrm{Hg}
$$

where $\mathrm{PAP}=$ mean pulmonary artery pressure, $\mathrm{LAP}=$ mean left atrial pressure, $\mathrm{CO}=$ cardiac output in milliliters per second, and 1330 dynes/mm Hg is a constant that converts millimeters of mercury to dynes.

Evaluation of endothelium-dependent and endothelium-independent vasodilatation before CPB (protocol 1). To demonstrate normal endothelium-dependent and -independent vasodilatation in normal animals, we assessed the responses to acetylcholine and nitric oxide in two experimental groups. Control animals $(n=5)$ were studied with both drugs after anesthesia and instrumentation only; animals treated with U46619 $(n=6)$ were studied while receiving a continuous infusion of the thromboxane $\mathrm{A}_{2}$ analog U46619 to preconstrict the pulmonary vasculature. Normally the pulmonary vasculature is essentially maximally vasodilated; therefore preconstriction is necessary to demonstrate normal endothelial and smooth muscle function.

U46619-treated animals received U46619 diluted in saline solution to a concentration of $2 \mu \mathrm{g} / \mathrm{ml}$ through a pulmonary arterial infusion line. The U46619 dose was titrated to achieve a PVR between 1800 and 2100 dyne $\mathrm{sec} \cdot \mathrm{cm}^{-5}$. This level of vasoconstriction was chosen after preliminary experiments demonstrating similar levels of PVR after CPB with DHCA. The mean dose was $0.07 \pm$ $0.02 \mu \mathrm{g} / \mathrm{kg}$ per minute. 
Endothelium-dependent and endothelium-independent vasodilatation after CPB with DHCA (protocol 2). To evaluate endothelium-dependent and -independent vasodilatation after CPB with DHCA, we supported six animals (DHCA) with CPB and arrested their hearts for 30 minutes as previously described in the $C P B$ section. Fifteen minutes after they were weaned from CPB, pulmonary vascular responses to acetylcholine and nitric oxide were assessed as described earlier.

Effect of nitric oxide synthase blockade before and after CPB (protocol 3). The nitric oxide synthase inhibitor $N \gamma$ nitro-L-arginine-methyl-ester (L-NAME) was used to examine the functional state of nitric oxide synthase in endothelial cells after CPB with DHCA. L-NAME is an analog of L-arginine and a competitive inhibitor of nitric oxide synthase. Administration of L-NAME results in pulmonary vasoconstriction only if endothelial cells are actively producing nitric oxide. L-NAME/control animals $(n=6)$ were treated with L-NAME $(5 \mathrm{mg} / \mathrm{kg}$ bolus via the pulmonary artery catheter) after anesthesia and instrumentation only. L-NAME/DHCA animals $(n=6)$ underwent CPB with 60 minutes of DHCA and were treated with L-NAME 15 minutes after being weaned from CPB. Data acquisition as described earlier was performed immediately before and 5, 10, 15, and 20 minutes after L-NAME was administered.

Effects of L-arginine supplementation on post-CPB pulmonary hypertension (protocol 4). L-Arginine is the substrate for nitric oxide synthase and is necessary for the production of nitric oxide. A decrease in the availability of $\mathrm{L}$-arginine to the endothelial cell after CPB could limit nitric oxide production and alter the balance between vasoconstrictors and vasodilators. To determine if substrate limitation is a factor in post-CPB pulmonary hypertension, the effects of $\mathrm{L}$-arginine supplementation during CPB were evaluated. No-L-arginine animals $(n=6)$ underwent $\mathrm{CPB}$ with 60 minutes of DHCA with no additional treatment. L-Arginine $(n=5)$ animals underwent CPB with 60 minutes of DHCA and received a continuous infusion of L-arginine at $20 \mathrm{mg} / \mathrm{kg}$ per minute throughout the CPB period (but not during DHCA). Data were collected as described earlier both before CPB and 15 minutes after weaning from CPB in both groups.

Statistical analysis. Analysis of variance was used to compare data between groups followed by the unpaired two-tailed $t$ tests. A $p$ value less than 0.05 was considered significant. Analysis of variance for repeated measures and Scheffe's post-hoc test were used to compare data within groups at different time points. Paired $t$ tests were used if only two time points were compared. Statistical analysis was performed with commercially available software (Statview II, Abacus Concepts, Inc., Berkeley, Calif.). All data are presented as means \pm standard error of the mean.

\section{Results}

Arterial blood gases and hemodynamic data. There were no significant differences in the arterial blood gases between the study and control groups in any of the protocols. Arterial blood gas data from the control, U46619, and DHCA groups (protocols 1 and 2) are displayed in Table I.

Cardiac outputs and mean pulmonary artery pressures for the four protocols are summarized in Tables IIA to IIC. Left atrial pressures were maintained at 4 to $9 \mathrm{~mm} \mathrm{Hg}$ with volume infusions and, although there was a trend toward higher left atrial pressure after DHCA, these differences did not achieve statistical significance.

Endothelium-dependent and endothelium-independent vasodilatation before CPB (protocol 1 ). Piglets studied at baseline (controls) were essentially maximally vasodilated and did not respond to either nitric oxide or acetylcholine (Fig. 2, $A$ ). PVR was significantly elevated by U46619 infusion (545 \pm 49 vs $1817 \pm 161 \mathrm{dyne} \cdot \mathrm{sec} \cdot \mathrm{cm}^{-5}$, baseline vs pre-acetylcholine, $p=0.0003)$. In the animals preconstricted with U46619, both acetylcholine and nitric oxide caused significant pulmonary vasodilatation with $34 \% \pm 6 \%(p=0.007$ pre-acetylcholine vs acetylcholine) and $39 \% \pm 4 \%(p=0.001$ prenitric oxide vs nitric oxide) decreases in PVR, respectively. These decreases in PVR demonstrate intact receptor-mediated endothelium-dependent and endothelium-independent vasodilatation (Fig. 2, B).

Endothelium-dependent and endothelium-independent vasodilatation after CPB with DHCA (protocol 2). CPB with DHCA resulted in a significant increase in PVR from $704 \pm 68$ to $1925 \pm 266$ dyne $\cdot \sec \cdot \mathrm{cm}^{-5}(p=0.003)$. After CPB with DHCA, acetylcholine did not alter PVR, with a $0 \% \pm 8 \%$ change ( $p=1.0$ pre-acetylcholine vs acetylcholine), indicating failure of receptor-mediated endotheliumdependent vasodilatation; nitric oxide caused a $32 \% \pm$ $4 \%$ decrease in PVR $(p=0.007$ pre-nitric oxide vs nitric oxide), demonstrating intact endothelium-independent vasodilatation and normal vascular smooth muscle function (Fig. 2, C). These data are consistent with previously reported clinical studies. ${ }^{2,3}$

Effect of nitric oxide synthase blockade before and after CPB (protocol 3). PVR increased significantly after DHCA $(611 \pm 100$ to $1993 \pm 399$ dyne $\left.\cdot \sec \cdot \mathrm{cm}^{-5}, p=0.01\right)$. There were no significant differences in the arterial blood gases between the groups. In both the L-NAME/control and $\mathbf{L}$ NAME/DHCA animals, inhibition of nitric oxide synthase with L-NAME significantly increased PVR (Fig. 3, $A$ and $B$ ). In the L-NAME/control piglets PVR increased from $526 \pm 53 \mathrm{dyne} \cdot \mathrm{sec} \cdot \mathrm{cm}^{-5}$ before L-NAME to $1813 \pm 253 \mathrm{dyne} \cdot \mathrm{sec} \cdot \mathrm{cm}^{ \pm 5}$ 20 minutes after L-NAME $(p=0.002)$. In the 

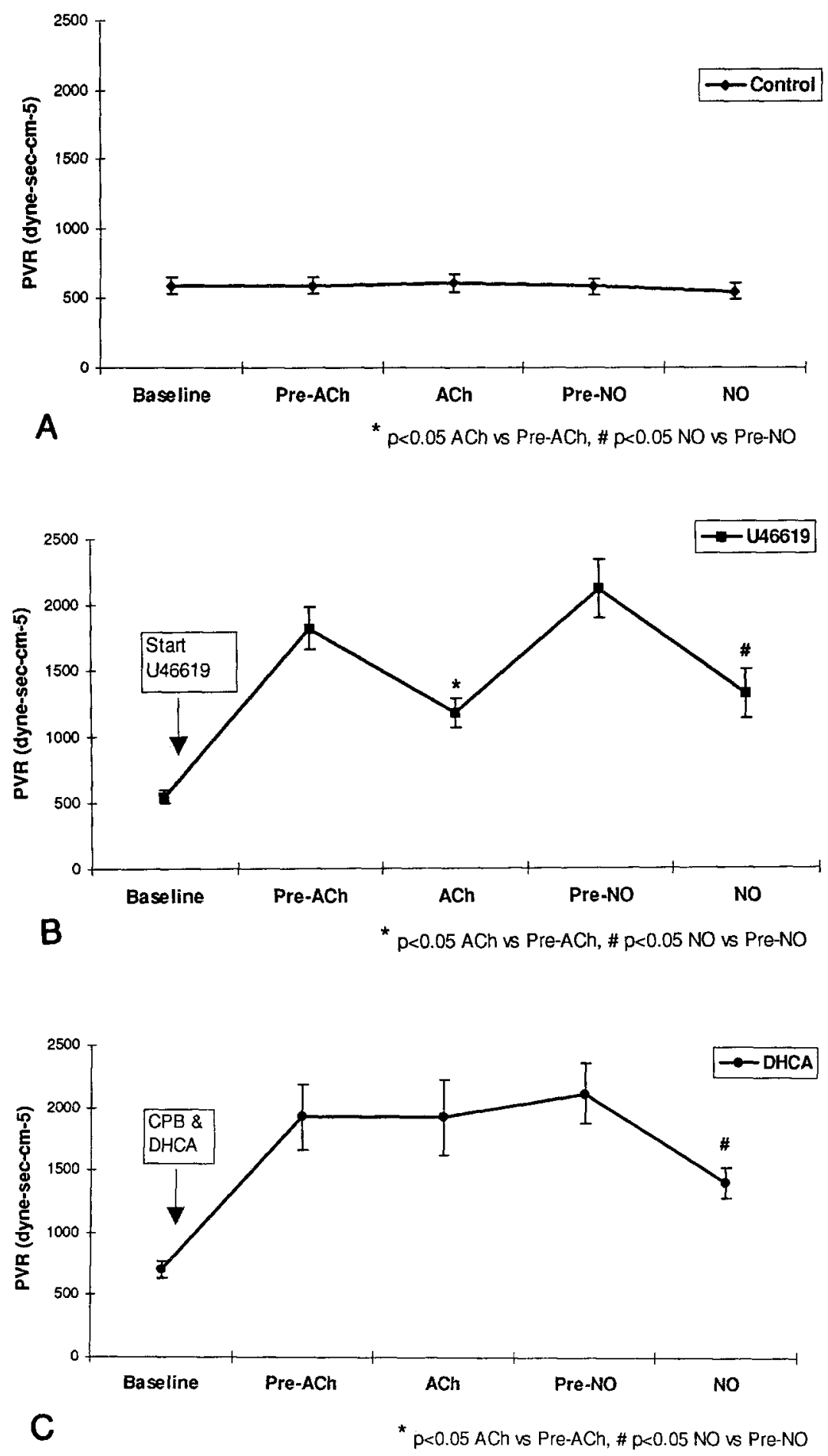

Fig. 2. PVR changes in response to endothelium-dependent (acetylcholine, $A C h$ ) and endotheliumindependent (nitric oxide, $N O$ ) vasodilators in control (A), U46619 (preconstricted with the thromboxane $A_{2}$ analog U46619) (B), and DHCA (C) animals. 

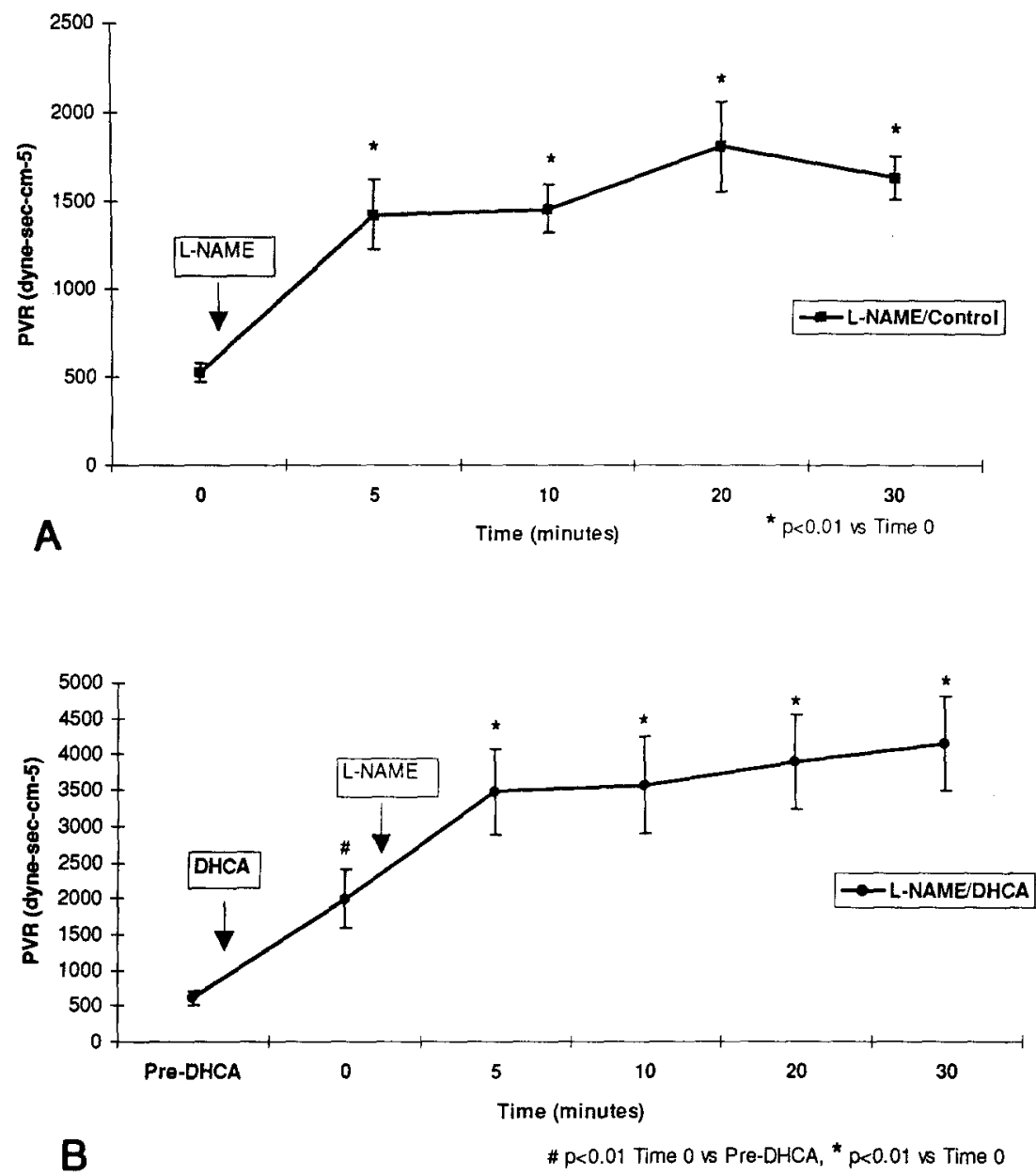

Fig. 3. Effects of nitric oxide synthase inhibition before (A) and after (B) CPB with DHCA. Inhibition of nitric oxide production significantly increases PVR both at baseline and after DHCA.

Table I. Arterial blood gases for protocol 1

\begin{tabular}{cccccc}
\hline & $p H$ & $\begin{array}{c}\mathrm{PaCO}_{2} \\
(\mathrm{~mm} \mathrm{Hg})\end{array}$ & $\begin{array}{c}\text { PaO } \\
(\mathrm{mm} \mathrm{Hg})\end{array}$ & Hematocrit & $\begin{array}{c}\text { Alveolar-arterial } \\
\text { gradient (mm Hg) }\end{array}$ \\
\hline Control & $7.40 \pm 0.01$ & $38.6 \pm 0.6$ & $208 \pm 12$ & $0.23 \pm 0.01$ & $74 \pm 7$ \\
U46619 & $7.40 \pm 0.03$ & $36.7 \pm 1.1$ & $210 \pm 3$ & $0.27 \pm 0.02$ & $50 \pm 5$ \\
DHCA & $7.43 \pm 0.01$ & $37.3 \pm 0.8$ & $195 \pm 9$ & $0.25 \pm 0.06$ & $113 \pm 23^{*}$
\end{tabular}

${ }_{*}^{*} p<0.025$ versus U46619 (unpaired $t$ test); no other significant differences.

L-NAME/DHCA animals, PVR was $1993 \pm 399$ dyne $\cdot \mathrm{sec} \cdot \mathrm{cm}^{ \pm 5}$ before $\mathrm{L}-\mathrm{NAME}$ and $3895 \pm 654$ dyne $\cdot \mathrm{sec} \cdot \mathrm{cm}^{-5} 20$ minutes after L-NAME $(p=$ 0.008 ); these results demonstrate that nitric oxide synthase in pulmonary endothelial cells continues to function and produce significant quantities of nitric oxide after CPB with DHCA. After blockade of nitric oxide synthase with L-NAME, PVR increased to a much higher level in the L-NAME/DHCA animals than in the L-NAME/control animals, suggesting that the pulmonary vasomotor tone in the absence of nitric oxide has changed. This finding is consistent with previous studies demonstrating increased production of vasoconstrictors after CPB. ${ }^{7-9}$

Effects of L-arginine supplementation on postCPB pulmonary hypertension (protocol 4). Supplementation with $\mathrm{L}$-arginine during $\mathrm{CPB}$ resulted in a slightly lower PVR relative to the no-L-arginine 
Table IIA, Hemodynamic data in protocols 1 and 2

\begin{tabular}{|c|c|c|c|c|c|c|c|c|}
\hline & \multicolumn{4}{|c|}{ Cardiac output $(\mathrm{ml} / \mathrm{min})$} & \multicolumn{4}{|c|}{ Mean PAP (mm Hg) } \\
\hline & Pre- $A C H$ & $A C H$ & Pre-NO & NO & Pre-ACH & $A C H$ & Pre-NO & NO \\
\hline Controls & $1618 \pm 103$ & $1510 \pm 89$ & $1602 \pm 99$ & $1602 \pm 128$ & $15.6 \pm 1.1$ & $14.0 \pm 0.5$ & $14.8 \pm 0.6$ & $13.8 \pm 0.4$ \\
\hline U46619 & $1188 \pm 43$ & $1387 \pm 98$ & $1020 \pm 50$ & $1019 \pm 90$ & $32.7 \pm 2.5$ & $26.2 \pm 2.0^{*}$ & $31.8 \pm 2.0$ & $21.8 \pm 2.2 \dagger$ \\
\hline DHCA & $845 \pm 58$ & $724 \pm 68^{*}$ & $725 \pm 50$ & $700 \pm 63$ & $25.5 \pm 2.3$ & $21.8 \pm 1.7^{*}$ & $24.5 \pm 1.9$ & $17.5 \pm 1.0 \dagger$ \\
\hline
\end{tabular}

$P A P$, Pulmonary artery pressure; $A C H$, acetylcholine; $N O$, nitric oxide; $D H C A$, deep hypothermic circulatory arrest.

Significant at $95 \%$ by analysis of variance: ${ }^{*} \mathrm{ACH}$ versus pre-ACH. $\uparrow \mathrm{NO}$ versus pre-NO.

Table IIB. Hemodynamic data in protocol 3

\begin{tabular}{lcccc}
\hline & Cardiac output $(\mathrm{ml} / \mathrm{min})$ & Mean PAP $(\mathrm{mm} \overline{\mathrm{Hg}})$ \\
\cline { 2 - 4 } & & & & L-NAME \\
& Pre-NAME - NAME & $(20 \mathrm{~min})$ & Pre-L-NAME & $(20 \mathrm{~min})$ \\
\hline Controls & $987 \pm 70$ & $873 \pm 59$ & $13.2 \pm 1.2$ & $26.5 \pm 3.3^{*}$ \\
DHCA & $899 \pm 125$ & $520 \pm 56^{*}$ & $25.5 \pm 1.3$ & $28.3 \pm 2.1$
\end{tabular}

${ }^{*} p<0.05$ versus pre-L-NAME (paired $t$ test).

group (Fig. 4); however, this difference was not statistically significant $(2404 \pm 436$ vs $2980 \pm 515$ dyne $\left.\cdot \mathrm{sec} \cdot \mathrm{cm}^{-5}, p=0.4\right)$. These data suggest that $\mathrm{L}$-arginine deficiency does not play a major role in post-CPB pulmonary hypertension. There were no significant differences in the arterial blood gases between the two groups.

\section{Discussion}

Many factors contribute to the development of pulmonary hypertension after $\mathrm{CPB}$. The factors that control pulmonary vasomotor tone are not completely understood and the effects of CPB on pulmonary vascular function have not been fully defined. The pulmonary endothelium produces both vasoconstrictors and vasodilators and is perhaps the most important determinant of pulmonary vascular tone. Previous studies have demonstrated both failure of pulmonary receptor-mediated endotheliumdependent vasodilatation ${ }^{2,7}$ and increased production of vasoconstrictors after $\mathrm{CPB} .^{7-10}$ This study used an intact piglet model to assess the effect of CPB on endothelium-dependent vasodilatation. In this model, CPB with DHCA results in the loss of receptor-mediated endothelium-dependent vasodilatation with preservation of endothelium-independent vasodilatation. Wessel and colleagues ${ }^{2}$ demonstrated that pulmonary vasodilatation in response to nitric oxide was intact in children studied after CPB, whereas acetylcholine-mediated vasodilatation was markedly diminished. Thus the pattern of injury in this experimental model is similar to that observed clinically. However, loss of the vasodilatory response
Table IIC. Hemodynamic data in protocol 4

\begin{tabular}{lrrrr} 
& Cardiac output (ml/min) & Mean PAP (mm Hg) \\
\cline { 2 - 5 } & Pre-DHCA & Post-DHCA & Pre-DHCA & Post-DHCA \\
\hline No L-arginine & $961 \pm 61$ & $744 \pm 79$ & $14.6 \pm 1.1$ & $32.1 \pm 1.1^{*}$ \\
L-Arginine & $1136 \pm 94$ & $795 \pm 63^{*}$ & $15.4 \pm 1.1$ & $29.0 \pm 2.8^{*}$ \\
\hline${ }^{*} p<0.05$ versus pre-DHCA (paired $t$ test). &
\end{tabular}

to acetylcholine by the pulmonary vasculature does not necessarily mean that pulmonary vascular endothelial cells are incapable of producing nitric oxide. This study demonstrates that the pulmonary endothelium continues to produce significant quantities of nitric oxide after $\mathrm{CPB}$, suggesting that nitric oxide synthase is functional despite loss of acetylcholinemediated vasodilatation. Although these studies clearly demonstrate continued production of significant quantities of nitric oxide after DHCA, the assays used are not quantitative; thus the actual amount of nitric oxide produced could still be diminished.

Vasodilatation in response to receptor-mediated endothelium-dependent vasodilators such as acetylcholine depends on a sequence of events beginning with binding of the agonist to a membrane bound receptor and ending with smooth muscle relaxation (see Fig. 1). ${ }^{4,5}$ Previous experiments have shown that the muscarinic receptor on the endothelial cell surface is coupled via a $G$ protein to the enzyme phospholipase C ${ }^{11,12}$ Stimulation of phospholipase $\mathrm{C}$ initiates the phosphatidylinositol pathway leading to a rise in intracellular calcium and increased conversion of $\mathrm{L}$-arginine to nitric oxide by nitric oxide synthase. The nitric oxide then diffuses to the vascular smooth muscle, causing an increase in cyclic guanosine monophosphate production and smooth muscle relaxation. Dysfunction at any of these intermediary steps would result in failure of vasodilatation in response to acetylcholine.

Previous studies have demonstrated that endothelial injury may result in a selective failure of receptor-mediated endothelium-dependent vasodilata- 


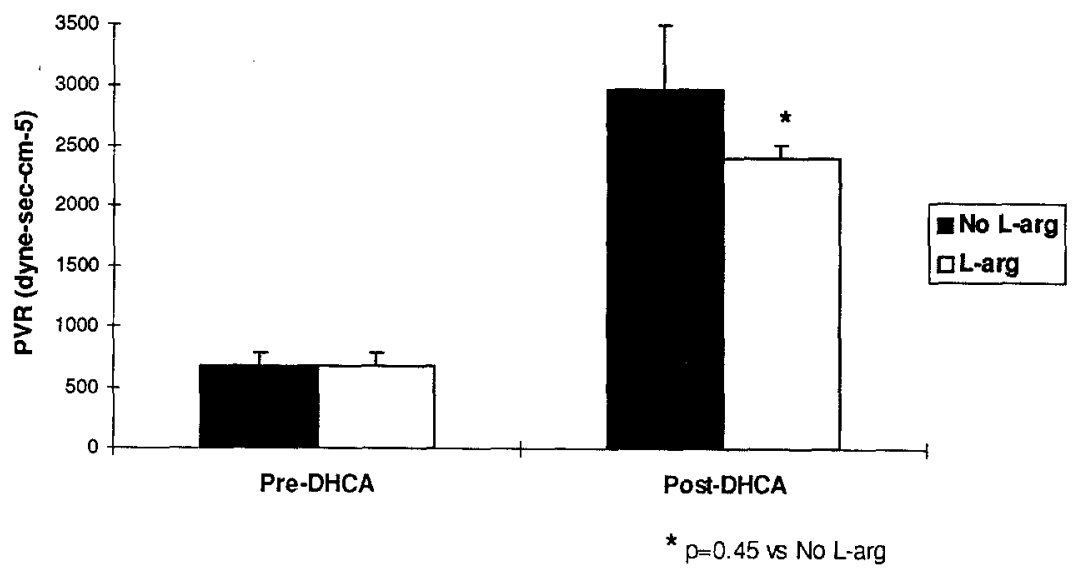

Fig. 4. Effects of L-arginine supplementation on post-DHCA PVR.

tion with preserved ability to produce nitric oxide. ${ }^{13}$ Evora, Pearson, and Schaff 5 evaluated endotheliumdependent vasodilatation in canine coronary arteries after global ischemia. Using in vitro coronary artery rings, they demonstrated loss of receptormediated endothelium-dependent vasodilatation with preservation of the responses to the receptorindependent endothelium-dependent vasodilators A23187 and phospholipase C. In these studies there was diminished response to sodium fluoride, which activates $G$ proteins directly, demonstrating specific $\mathrm{G}$ protein dysfunction after ischemia/reperfusion. Seccombe, Pearson, and Schaff ${ }^{12}$ showed that exposure of isolated coronary artery rings to oxygenderived free radicals also results in a $G$ protein injury that produces a selective impairment of receptor-mediated endothelium-dependent vasodilatation. A similar pattern of endothelial injury has been reported in early atherosclerosis. ${ }^{14} \mathrm{G}$ proteins have also been shown to be involved in the regulation of nitric oxide production in response to changes in shear stress. ${ }^{15,16}$ Thus a $G$ protein injury could result in dysfunctional endothelial vasoregulation. Shafique and colleagues ${ }^{7}$ have demonstrated in an in vitro model that after CPB acetylcholine may cause vasoconstriction rather than vasodilatation in isolated pulmonary vessels. The mechanism of this change is unknown but may be due to production of a vasoconstricting prostanoid.

The current study demonstrates that in this in vivo animal model, CPB with DHCA produces failure of receptor-mediated endothelium-dependent vasodilatation in the pulmonary vasculature with preserved ability to produce nitric oxide. This finding is consistent with clinical studies demonstrating an impaired response to acetylcholine with preserved response to inhalational nitric oxide. ${ }^{2,3,17}$ The current study shows that the impaired response to acetylcholine is not due to smooth muscle dysfunction, failure of nitric oxide synthase, or nitric oxide synthase substrate (L-arginine) limitation. These observations suggest that $\mathrm{CPB}$ produces a selective pulmonary endothelial injury. The data suggest that the defect causing failure of receptor-mediated endothelium-dependent vasodilatation occurs upstream of nitric oxide synthase and hence might be located at the level of the receptor, $G$ protein, or phospholipase $\mathrm{C}$ second messenger system (see Fig. 1). Previous studies have demonstrated selective $G$ protein dysfunction in the coronary artery after global ischemia or exposure to oxygen-derived free radicals. ${ }^{5,12}$ The findings of the current study suggest that a similar injury may occur in the pulmonary vasculature, impairing the ability of the endothelial cell to modulate vasomotor tone and leading to an imbalance between vasoconstrictors and vasodilators.

The current study has several limitations. The use of an intact animal model mimics the clinical situation more closely than isolated vessel preparations. However, inasmuch as important variables such as changing intravascular shear stress and the interactions between blood elements and the endothelium are included, these variables cannot be tightly controlled. Also, the experimental model directly assesses neither $G$ protein function nor the role of increased vasoconstrictor production during CPB. Endothelium-derived vasoconstrictors, including thromboxane $\mathrm{A}_{2}$ and endothelin 1, have been shown to be important in post-CPB pulmonary hyperten- 
sion. $^{7-10}$ The level of vasoconstriction after LNAME was much greater in animals after DHCA than in controls, suggesting that the basal tone in the absence of nitric oxide is higher after DHCA, possibly because of increased vasoconstrictor levels. Also, although these studies demonstrate a specific defect in muscarinic receptor-mediated nitric oxide production, other receptor systems may be unaffected.

In summary, we have used an intact animal model to examine pulmonary endothelial function after $\mathrm{CPB}$. The findings are consistent with prior clinical studies and suggest that there is a specific impairment of receptor-mediated endothelium-dependent vasodilatation with continued production of nitric oxide by the endothelium and preserved vascular smooth muscle response to nitric oxide. It must be emphasized that although these studies demonstrate continued nitric oxide production after DHCA, these assays are not quantitative; thus the amounts of nitric oxide produced may well be decreased. In conclusion, this study suggests that CPB disrupts some of the regulatory functions of the endothelial cell, alters the balance between vasoconstriction and vasodilatation, and ultimately results in pulmonary hypertension.

\section{REFERENCES}

1. Schranz D, Zepp F, Iversen S, et al. Effects of tolazoline and prostacyclin on pulmonary hypertension in infants after cardiac surgery. Crit Care Med 1992;20:1243-9.

2. Wessel DL, Adatia I, Giglia TM, Thompson JE, Kulik TJ. Use of inhaled nitric oxide and acetylcholine in the evaluation of pulmonary hypertension and endothelial function after cardiopulmonary bypass. Circulation 1993;88[Pt 1]: 2128-38.

3. Wessel DL. Inhaled nitric oxide for the treatment of pulmonary hypertension before and after cardiopulmonary bypass. Crit Care Med 1993;21:s344-5.

4. Moncada S, Higgs A. The L-arginine-nitric oxide pathway. $N$ Engl J Med 1993;329:2002-12.
5. Evora PRB, Pearson PJ, Schaff HV. Impaired endotheliumdependent relaxation after coronary reperfusion injury: evidence for G-protein dysfunction. Ann Thorac Surg 1994;57: 1550-6.

6. Flavahan NA, Vanhoutte PM. G-proteins and endothelial responses. Blood Vessels 1990;27:218-29.

7. Shafique T, Johnson RG, Dai HB, Weintraub RM, Sellke FW. Altered pulmonary microvascular reactivity after total cardiopulmonary bypass. J Thorac Cardiovasc Surg 1993;106: 479-86.

8. Cave AC, Manche A, Derias NW, Hearse DJ. Thromboxane $\mathrm{A}_{2}$ mediates pulmonary hypertension after cardiopulmonary bypass in the rabbit. J Thorac Cardiovasc Surg 1993;106:95967.

9. Faymonville M-E, Deby-Dupont G, Larbuisson R, Deby C, Bodson L, Limet $R$. Prostaglandin $E_{2}$, prostacyclin, and thromboxane changes during nonpulsatile cardiopulmonary bypass in humans. J Thorac Cardiovasc Surg 1986;91:858-66.

10. Kirshbom PM, Tsui SS, DiBernardo LR, et al. Blockade of endothelin converting enzyme reduces pulmonary hypertension after cardiopulmonary bypass and circulatory arrest. Surgery 1995;118:440-5.

11. Hohlfeld J, Liebau S, Forstermann U. Pertussis toxin inhibits contractions but not endothelium-dependent relaxations of rabbit pulmonary artery in response to acetylcholine and other agonists. J Pharmacol Exp Ther 1990;252:260-4.

12. Seccombe JF, Pearson PJ, Schaff HV. Oxygen radicalmediated vascular injury selectively inhibits receptor-dependent release of nitric oxide from canine coronary arteries. J Thorac Cardiovasc Surg 1994;107:505-9.

13. Pearson PJ, Lin PJ, Schaff HV. Global myocardial ischemia and reperfusion impair endothelium-dependent relaxations to aggregating platelets in the canine coronary artery. J Thorac Cardiovasc Surg 1992;103:1147-54.

14. Flavahan NA. Atherosclerosis or lipoprotein-induced endothelial dysfunction. Circulation 1992;85:1927-38.

15. Ohno M, Gibbons GH, Dzau VJ, Cooke JP. Shear stress elevates endothelial cGMP: role of a potassium channel and G protein coupling. Circulation 1993;88:193-7.

16. Kuchan MJ, Jo H, Frangos JA. Role of $G$ proteins in shear stress-mediated nitric oxide production by endothelial cells. Am J Physiol 1994;267:C753-8.

17. Journois D, Pouard P, Mauriat P, Maihere T, Vouhe P, Safran D. Inhaled nitric oxide as a therapy for pulmonary hypertension after operations for congenital heart defects. J Thorac Cardiovasc Surg 1994;107:1129-35. 